\title{
The Isolation of Glycerol-Fermenting and Lipolytic Bacteria from the Rumen of the Sheep
}

\author{
By P. N. HOBSON AND S. O. MANN \\ The Rowett Research Institute, Bucksburn, Aberdeen
}

(Received 28 October 1960)

\begin{abstract}
SUMMARY
Facultatively anaerobic bacteria appear to play little part in glycerol fermentation in the sheep rumen. Amongst the most important members of the glycerol-fermenting flora are strict anaerobes of the group Selenomonas ruminantium var. lactilyticas. Three isolates of a different group of strictly anaerobic curved Gram-negative rods, which hydrolyse linseed oil and tributyrin as well as fermenting glycerol, were obtained in numbers which suggest they are amongst the more important lipolytic bacteria in the rumen. The main product of fermentation of glycerol by the selenomonads and the lipolytic bacteria is propionic acid, but other acids are also formed. The properties of these bacteria and some others isolated during the experiments are described. All the bacteria appear to be normal inhabitants of the rumen of sheep fed a number of different rations. The numbers of these organisms were not appreciably increased by feeding glycerol or triglycerides to the animals.
\end{abstract}

\section{INTRODUCTION}

Over the last few years a number of papers have been published about the effects of dietary fats and oils on the digestibility of foodstuff components. Also, the hydrogenation of unsaturated fatty acids in the rumen has been investigated by a number of workers (see review by Garton, 1960). During investigations on the nitrogen metabolism of ruminants Dr M. I. Chalmers of this Institute found that the addition of oils or fats to sheep rations had a marked effect on the ruminal ammonia concentrations. The separate components of these triglycerides (fatty acids, glycerol) also affected ammonia concentrations as might be expected, since it has been shown that triglycerides of long-chain fatty acids can be rapidly hydrolysed by mixed rumen organisms (Garton, Hobson \& Lough, 1958; Garton, Lough \& Vioque, 1961). The work described here was undertaken to see whether some of the bacteria presumed to be responsible for the hydrolysis of dietary glycerides and the fermentation of the glycerol formed could be isolated and studied in more detail. Also to be examined was the question whether such bacteria were an intrinsic part of the normal rumen flora, or whether they increased in numbers (or differed in types) in the rumens of sheep being fed different amounts of glycerides or glycerol. Since the ruminal ammonia concentrations were altered by feeding these substances it was of interest to see whether glycerol-fermenting or lipolytic bacteria utilized or produced any large amount of ammonia during growth. A number of glycerol-containing media were used in an endeavour to isolate not only strictly anaerobic rumen bacteria, but also facultative anaerobes and bacteria which do not need the exacting conditions of 
some rumen bacteria (see review by Bryant, 1959). Acetate was included in some of the media in an attempt to isolate bacteria which fermented glycerol and acetate to butyric acid (compare Clostridium tyrobutyricum) since the experiments with whole rumen contents suggested that propionic acid was not the only end product of glycerol fermentation in the rumen as suggested by Johns (1953), and acetate is a normal constituent of rumen fluid. Linseed oil was chosen as substrate for the lipolytic bacteria since it was being fed to some of the sheep in linseed cake and as added oil; further, the component fatty acids of the glycerides of linseed oil are similar to those of total grass lipids.

\section{METHODS}

\section{Media}

Some of the important bacteria isolated from the rumen will not grow under the conditions usually used for growth of 'strict anaerobes' (for example clostridia). Special techniques for the isolation of these bacteria have been devised and these are briefly outlined below. In addition to a low $E_{h}$ and $\mathrm{CO}_{2}$ some rumen bacteria need growth factors found in rumen fluid, and this is often included in media for isolation of rumen bacteria.

General methods. The technique used for the preparation of the media specified as ' incubated under $\mathrm{CO}_{2}$ ' (no. 4-14) was based on that originated by Hungate (1950). In this method the various solutions making up the media are saturated with $\mathrm{CO}_{2}$ and mixed under a stream of oxygen-free $\mathrm{CO}_{2}$, and contain a reducing agent which brings the $E_{h}$ below that at which resazurin is colourless. The oxidation-reduction potential of the media described in this paper, measured between a calomel and a platinum electrode, was $c$. $-350 \mathrm{mV}$. Small amounts of these media (c. $10 \mathrm{ml}$.) were dispensed into 6 in. $\times \frac{5}{8}$ in. tubes under a stream of $\mathrm{CO}_{2}$ and tightly stoppered with rubber bungs. Larger volumes of media were prepared in rubber-stoppered bottles using a similar technique. All inoculations of this type of medium were carried out under a stream of $\mathrm{CO}_{2}$. Any media showing a trace of pink oxidized resazurin were discarded as the strictly anaerobic rumen bacteria will not grow under such conditions.

General constituents of media. Mineral solution (a) contained (g./l.): $\mathrm{KH}_{2} \mathrm{PO}_{4}, \mathbf{3 \cdot 0}$; $\left(\mathrm{NH}_{4}\right)_{2} \mathrm{SO}_{4}, 6 \cdot 0 ; \mathrm{NaCl}, 6.0 ; \mathrm{MgSO}_{4}, 0.6 ; \mathrm{CaCl}_{2}, 0 \cdot 6$. Mineral solution (b) contained (g./l.): $\mathrm{K}_{2} \mathrm{HPO}_{4}, \mathbf{3} \cdot \mathbf{0}$. Rumen fluid was prepared by straining rumen contents (freshly obtained from a hay-fed sheep) through gauze and centrifuging at $62,000 \mathrm{~g}$ for $10 \mathrm{~min}$. The clear liquid was kept for not more than a few days at $2^{\circ}$ before use.

\section{Media used for glycerol-fermenting bacteria}

Media 1 to 3 were used for the isolation of rumen bacteria less exacting in requirements for a low $E_{h}$ and presence of $\mathrm{CO}_{2}$. Medium 1 contained, per $100 \mathrm{ml}$.: Bactocasitone, 1.5 g.; Difco yeast extract, 0.5 g.; NaCl, 0.5 g.; L-cystine, 0.075 g.; thioglycollic (mercaptoacetic) acid, $0.03 \mathrm{ml}$; agar, $0.075 \mathrm{~g}$.; glycerol, $1 \mathrm{ml}$.; bromocresol purple, $\mathbf{0} \cdot 1 \mathrm{ml}$. of $1.6 \%(\mathrm{w} / \mathrm{v})$ ethanolic solution; water to $100 \mathrm{ml}$. All the constituents except the glycerol, which was added as a sterile filtered solution, were autoclaved together at $120^{\circ}$ for $15 \mathrm{~min}$. The medium was dispensed in $9 \mathrm{ml}$. amounts in tubes plugged with cotton wool and tenfold dilutions of rumen contents prepared in this medium. Incubation was in air. Medium 2. This medium was like medium 1, but contained agar 2 g., and was incubated in plates in a McIntosh \& Fildes anaero- 
bic jar under hydrogen. Medium 3 contained: mineral solution (a), $15 \mathrm{ml}$.; mineral solution (b), $15 \mathrm{ml}$.; rumen fluid, $20 \mathrm{ml}$; yeast extract, 0.25 g.; glycerol, $1 \mathrm{ml}$; agar, $2 \mathrm{~g}$.; water, $49 \mathrm{ml}$.; bromocresol purple, $0 \cdot 1 \mathrm{ml}$. of $1.6 \%(\mathrm{w} / \mathrm{v})$ ethanolic solution. All the constituents except glycerol, which was added as a filtered solution, were autoclaved together. This medium was incubated in plates in a McIntosh \& Fildes anaerobic jar under hydrogen, except where noted.

Media 4 to 14 were used for the isolation or testing of rumen bacteria exacting in requirements for a low $E_{h}$ and $\mathrm{CO}_{2}$, and were prepared as described under General Methods and incubated under $\mathrm{CO}_{2}$. Medium 4 contained mineral solution $(a), 15 \mathrm{ml}$.; mineral solution (b), $15 \mathrm{ml}$; rumen fluid, $40 \mathrm{ml}$; Difco yeast extract, $0 \cdot 25 \mathrm{~g}$; ; water, $29 \mathrm{ml}$; bromocresol purple, $0 \cdot 1 \mathrm{ml}$. of $1 \cdot 6 \%(\mathrm{w} / \mathrm{v})$ ethanolic solution; glycerol, $1 \mathrm{ml}$.; sodium acetate, hydrated, 1.49 g.; $\mathrm{NaHCO}_{3}, 0 \cdot 4$ g.; cysteine $\mathrm{HCl}, 0 \cdot 05$ g.; $\mathrm{pH} 6 \cdot 8$. The mineral solutions, rumen fluid, yeast extract, indicator and water were autoclaved together at $120^{\circ}$ for $15 \mathrm{~min}$. Immediately on removing from the autoclave oxygen-free $\mathrm{CO}_{2}$ was bubbled through the solution and the flask stoppered. The glycerol, acetate, bicarbonate and cysteine were then added as a sterile filtered solution, and the medium dispensed in $9 \mathrm{ml}$. amounts. Tenfold dilutions of rumen contents were usually made directly into this medium. Medium 5. This medium was like medium 4 except that bromocresol purple was omitted and agar $(2 \%, w / v)$ and resazurin $(0.0001 \%, \mathrm{w} / \mathrm{v})$ were added. Medium 6 was like medium 5 , but without agar. Medium 7 was like medium 4, except that sodium acetate was omitted and the glycerol was replaced by the appropriate 'sugar' to $0.5 \%$ or $1 \%(\mathrm{w} / \mathrm{v})$. Medium 8 contained per $100 \mathrm{ml}$.: mineral solution (a), $15 \mathrm{ml}$; mineral solution $(b), 15 \mathrm{ml}$; rumen fluid, $20 \mathrm{ml}$; water, $49 \mathrm{ml}$; $\mathrm{NaHCO}_{3}, 0.4 \mathrm{~g}$; glycerol, $1 \mathrm{ml}$; cysteine $\mathrm{HCl}$, $0.05 \mathrm{~g}$; ; resazurin, $0.1 \mathrm{ml}$. of $0.1 \%(\mathrm{w} / \mathrm{v})$ solution. Medium 9 was like medium 8 but contained in addition yeast extract, $\mathbf{0} \cdot 25 \mathrm{~g}$. After incubation for 2 days ammonia in inoculated and uninoculated media was determined by the method of Conway (1957). The lipolytic bacteria were also tested in media 8 and 9.

\section{Media used for lipolytic bacteria}

These media were prepared and incubated under $\mathrm{CO}_{2}$ as described under General Methods. To prevent alteration of the linseed oil by heating, the oil was taken from the lower part of a deep bottle kept at $2^{\circ}$ and added to media without sterilization. No bacteria were ever found to grow from such samples of oil placed in uninoculated media. Saliva was used as an emulsifying agent for the linseed oil.

Saliva-based medium. Medium 10 contained, per 100 ml.: glucose, $0 \cdot 2$ g.; yeast extract, $0.5 \mathrm{~g}$.; $\mathrm{NaCl}, 0.5 \mathrm{~g}$.; cysteine $\mathrm{HCl}, 0 \cdot 1 \mathrm{~g}$.; sheep parotid saliva, $99 \mathrm{ml}$.; linseed oil, $1 \mathrm{ml}$.; resazurin, $0.1 \mathrm{ml}$. of $0.1 \%(\mathrm{w} / \mathrm{v})$ solution; $\mathrm{K}_{2} \mathrm{HPO}_{4}, 0.087 \mathrm{~g}$.; $\mathrm{KH}_{2} \mathrm{PO}_{4}$, $1 \cdot 29$ g.; final $\mathrm{pH} 6 \cdot 9$. The phosphates, yeast, $\mathrm{NaCl}$, cysteine and resazurin were mixed in $95 \mathrm{ml}$. saliva, gassed with $\mathrm{CO}_{2}$ and heated in boiling water until the dye was reduced. The bottle was then stoppered tightly under $\mathrm{CO}_{2}$ and autoclaved at $120^{\circ}$ for $15 \mathrm{~min}$. The linseed oil was then added as an emulsion and the glucose as a concentrated filtered solution in amounts sufficient to bring the constitution of the medium to that given above. The complete medium was then mechanically shaken to produce an even emulsion. Medium 10 was dispensed in $9 \mathrm{ml}$. amounts and inoculated with $1 \mathrm{ml}$. portions of tenfold dilutions of rumen contents made in a solution of phos- 
phates, cysteine and resazurin in saliva in the concentrations used in the medium. The dilution blanks were autoclaved under $\mathrm{CO}_{2}$ and dilutions made in an apparatus enabling $\mathrm{CO}_{2}$ to be continuously bubbled through the blanks.

Rumen fluid-based media (11 to 13). Medium 11 contained, per $100 \mathrm{ml}$. : mineral solution (a), $15 \mathrm{ml}$.; mineral solution (b), $15 \mathrm{ml}$; ; rumen fluid, $40 \mathrm{ml}$.; water, $29 \mathrm{ml}$.; resazurin, $0.1 \mathrm{ml}$. of $0.1 \%(\mathrm{w} / \mathrm{v})$ solution; $\mathrm{NaHCO}_{3}, 0.4 \mathrm{~g}$; ; cysteine $\mathrm{HCl}, 0.05 \mathrm{~g}$; glucose, $\mathbf{0} \cdot 1 \mathrm{~g}$.; linseed oil, $1 \mathrm{ml}$. The minerals, rumen fluid, water and resazurin were autoclaved together at $120^{\circ}$ for $15 \mathrm{~min}$. The $\mathrm{NaHCO}_{3}$, cysteine and glucose were added as a sterile filtered aqueous solution, and the linseed oil as a $50 \%(\mathrm{v} / \mathrm{v})$ emulsion in sterile rumen fluid. The completed medium no. 11 was shaken under $\mathrm{CO}_{2}$ to emulsify the oil and then dispensed in $9 \mathrm{ml}$. amounts. Tenfold dilutions of rumen contents were made under $\mathrm{CO}_{2}$ in a sterile solution of minerals $(a)+(b)$, cysteine and resazurin in the percentage proportions used in the medium. Portions $(1 \mathrm{ml}$.$) of$ each dilution were added to $9 \mathrm{ml}$. medium. Medium 12 was like medium 11 except that glucose was omitted. Medium 13 was like medium 12 but containing $2 \%(\mathrm{w} / \mathrm{v})$ agar. The linseed oil emulsion was added to medium 13 at a temperature of about $70^{\circ}$ and it was shaken immediately so that the agar did not set whilst the oil was being emulsified. Medium 13 was dispensed and kept at $50^{\circ}$ until inoculated, after which the tubes were rolled under cold water; dilutions of rumen contents were made directly in this medium. Medium $13+1 \%(\mathrm{v} / \mathrm{v})$ tributyrin in place of oil was used to test for esterase activity.

Casitone + yeast extract-based medium. Medium 14, was like medium 12 except that the rumen fluid was replaced by Bacto-casitone (1.5 g.) and yeast extract (0.25 g.).

\section{Properties of glycerol-fermenting bacteria}

Biochemical tests on selenomonads. Hydrogen sulphide was tested for in medium 6 by lead acetate paper, gelatin liquefaction in the same medium with sterile gelatin + charcoal tablet added (Kohn, 1953), and nitrate reduction in this medium with $0.2 \%(\mathrm{w} / \mathrm{v}) \mathrm{KNO}_{3}$ added. Indole and Voges-Proskauer tests were made in a medium similar to medium 6 but with $0.5 \%(\mathrm{w} / \mathrm{v})$ glucose in place of glycerol, Bacto-casitone added to $1 \%(\mathrm{w} / \mathrm{v})$ and the rumen fluid decreased to $10 \%(\mathrm{v} / \mathrm{v})$. Products of glycerol fermentation were determined in medium 6 with rumen fluid decreased to $10 \%(\mathrm{v} / \mathrm{v})$. Fermentation reactions were tested in medium 7 .

The properties of other bacteria. The fermentation reactions of the Clostridium and Aerobacter spp. were tested in peptone water and other reactions by the methods given in Manual of Microbiological Methods (1957). Products of glycerol fermentation by the clostridia were determined in cultures grown in medium 1 .

Motility tests were made on selenomonad cultures grown $17 \mathrm{hr}$. in medium $6+0 \cdot 1 \%$ $(\mathrm{w} / \mathrm{v})$ glucose replacing glycerol. Organisms were examined in sealed capillary tubes and stained for flagella by Liefson's method (Manual of Microbiological Methods, 1957).

\section{Properties of lipolytic bacteria}

Biochemical tests. Fermentation reactions were tested in medium 12 or in medium 14 (without oil) with the 'sugar' at $1 \%$ or $0.5 \%(\mathrm{w} / \mathrm{v})$ concentration and bromocresol purple added. Hydrogen sulphide and indole production were tested in medium 14 without oil but with glycerol, nitrate reduction in the same medium with 
$0 \cdot 1 \%(\mathrm{w} / \mathrm{v}) \mathrm{KNO}_{3}$ added, and gelatin hydrolysis also in this medium with a gelatin + charcoal tablet added.

Motility tests were made on cultures grown $17 \mathrm{hr}$. in medium $14+0 \cdot 1 \%(\mathrm{v} / \mathrm{v})$ glycerol in place of oil. Organisms were examined in wet preparation by darkground illumination and stained for flagella by Liefson's method (Manual of Microbiological Methods, 1957).

\section{General Methods}

Determination of lipolytic activity. The whole culture, or uninoculated medium blank (10 ml.) was brought to $\mathrm{pH} 5 \cdot 6-5 \cdot 8$ by addition of $2 \mathrm{~N}-\mathrm{HCl}$ and extracted with $3 \times 10 \mathrm{ml}$. portions of ether. The ether extract was then washed with successive $10 \mathrm{ml}$. portions of water saturated with ether until the washings were at $\mathrm{pH} \mathrm{6 \cdot 5-7}$. The ether was removed by distillation (for the last few minutes in vacuo) the oily residue dissolved in $10 \mathrm{ml} .95 \%(\mathrm{v} / \mathrm{v})$ ethanol in water and titrated with $0.05 \mathrm{~N}-\mathrm{NaOH}$ (phenol red as indicator). In preliminary experiments the results obtained by this method were checked against those obtained by extraction and weighing of the free fatty acids by the methods given in the previous paper (Garton et al. 1961).

Determination of fermentation products. Volatile fatty acids were steam-distilled from the acidified medium after removal of cells (Friedemann, 1938) and analysed qualitatively by paper chromatography (Elsden \& Lewis, 1953) or quantitatively by chromatography on celite columns (Bueding \& Yale, 1951). Lactic acid and formic acid were determined colorimetrically (Barker \& Summerson, 1941; Grant, 1947) and succinic acid by a manometric method (Umbreit, Burris \& Stauffer, 1957). Glycerol was determined by the method of Lambert \& Neish (1950).

Stock cultures. Stock cultures of the clostridia were kept in Robertson's cooked meat medium and the Aerobacter strains on nutrient agar slopes. The selenomonads were kept initially at $-20^{\circ}$ on slopes of medium 5 , and subcultured every 10-14 days. Later slopes stored at $2^{\circ}$ were found to keep just as effectively. Cultures were also freeze-dried in $7 \cdot 5 \%(\mathrm{w} / \mathrm{v})$ glucose serum broth and in $10 \%$ whole milk. These dried cultures kept at $2^{\circ}$ could be revived after 3 months. The lipolytic organisms were maintained at $2^{\circ}$ on slopes of medium 14 with agar + glycerol in place of oil, transferred every 4 weeks. Cultures freeze-dried as previously described did not revive.

Sheep rations and the collection of rumen samples. The basal ration consisted of a mixture of linseed cake meal, casein and a concentrate mixture (ground maize, crushed oats, bran) with hay fed separately. Sheep $8,8 \mathrm{~N}, 186,97$ and 6 received this ration except when recorded as 'fed oil', which meant that $\mathbf{4 0} \mathrm{g}$. linseed oil/day was added to the ration, or 'fed glycerol', which meant that $20 \mathrm{~g}$. glycerol/day was added. Sheep 44 always had the basal diet + glycerol. Sheep 9 received a diet of hay and grass cubes only. Samples were taken via rumen cannulas about $3 \mathrm{hr}$. after feeding.

\section{RESULTS}

\section{Glycerol-fermenting bacteria}

Growth in a medium without rumen fluid. Rumen contents from sheep 6 were diluted in medium 1 and incubated for 3 days. Cultures which showed acid formation (up to $1 / 10^{6}$ dilution) were subcultured on solid medium 2 and incubated for 2 days. Acid-producing colonies were transferred to a liquid medium (medium 1 
without agar). A mixed flora grew in the initial cultures, but the chief bacteria which grew on subculture were large, thick Gram-positive rods from dilutions up to $1 / 10^{4}$. From the initial $1 / 10^{5}$ and $1 / 10^{6}$ dilutions Gram-positive cocci were obtained which gave a weak acid reaction with glycerol; this activity was lost on subculture. The Gram-positive rods were $2 \mu$ to $5 \mu \times 1 \mu$, did not grow aerobically, on blood agar they gave $\beta$-haemolysis. Colonies were $2.5 \mathrm{~mm}$. in diameter, smooth, whitish, translucent with slightly raised centre and uneven edge. Glycerol was fermented to give acid, and glucose, maltose, lactose and sucrose gave acid and gas; mannitol and salicin were not fermented. In litmus milk a stormy clot reaction was given and the lecithinase test was positive within $48 \mathrm{hr}$. The organisms were identified as Clostridium perfringens (Welchii).

Growth in a medium with rumen fluid incubated under hydrogen. Tenfold dilutions of rumen contents from sheep 6 (fed glycerol) were prepared in sterile saline, and $1 \mathrm{ml}$. portions of the dilutions mixed with medium 3 in Petri dishes and incubated under hydrogen for 3 days. Acid-forming colonies appeared up to $1 / 10^{3}$ dilution. The primary colonies were subcultured into medium 3 without agar, and further subcultures made from those cultures which showed acid formation. From the initial $1 / 10^{3}$ dilution some very small Gram-positive rods were obtained which did not survive further subculture. From the $1 / 10^{2}$ dilution Gram-negative rods of different sizes were obtained; they were non-motile and straight or slightly curved with some variation in length. Organisms grown aerobically on medium 3 had large capsules. Anaerobically very small capsules were formed and the organisms tended to be short and coccoid. Grown anaerobically and aerobically these bacteria were non-haemolytic. Colonies growing aerobically at $38^{\circ}$ on medium 3 containing different amounts of rumen fluid were always opaque, mucoid, raised with entire edge, creamy white and about $3.5 \mathrm{~mm}$. diameter; anaerobically the colonies were 0.5-1.75 $\mathrm{mm}$. diameter and not mucoid. These bacteria fermented dulcitol, inositol, glycerol, mannitol, sorbitol, xylose, arabinose, rhamnose, aesculin, salicin, glucose, galactose, lactose, trehalose, dextrin and starch, giving acid and gas; adonitol and inulin were not fermented. Litmus milk after $17 \mathrm{hr}$. gave acid without a clot; at $48 \mathrm{hr}$. a soft clot had formed. Catalase reaction, nitrate reduction, Voges-Proskauer reaction and growth in Koser's citrate medium were all positive. Indole, methyl red and Eijkman tests, gelatin liquefaction and examinations for motility were all negative. The bacteria were classified as Aerobacter aerogenes.

Growth in media with rumen fluid incubated under carbon dioxide. Cultures were made of dilutions of rumen contents from sheep 6 (fed glycerol), 8, 9 and 44. Medium 4 was used for all samples except that from sheep 8 , in which case the medium base was modified by adding rumen fluid to only $20 \%(\mathrm{v} / \mathrm{v})$ and agar to $2 \%(\mathrm{w} / \mathrm{v})$ and omitting the indicator. This modified medium 4 was used without glycerol or acetate, or with glycerol alone, acetate alone, or glycerol + acetate in the concentrations given under Methods. These media were inoculated with dilutions of rumen fluid (from sheep 8) prepared in a fluid similar to that of Doetsch, Robinson \& Shaw (1952). All four media gave from sheep 8 a growth consisting predominantly of curved Gram-negative rods up to $1 / 10^{\circ}$ dilution. Growth was denser in the media with added glycerol. From the medium + glycerol alone isolations were made of a curved Gram-negative rod (A/10/B), and a very small Gram-negative coccus, the latter not surviving continued subculture. 
Cultures from sheep 44 showed a growth predominantly consisting of curved Gram-negative rods up to $1 / 10^{12}$ dilution. No isolations were made from this experiment.

Cultures from sheep 6 (fed glycerol) made in medium 4 gave good growth and acid formation up to $1 / 10^{8}$ dilution; again Gram-negative rods predominated. From the $1 / 10^{7}$ and $1 / 10^{8}$ dilutions subcultures were made into medium 5 . The pure cultures finally obtained and examined in detail were all from the $1 / 10^{8}$ dilution. There were six isolates (numbered, 3, 6, 7, 8, 9, 12) all strictly anaerobic Gram-negative curved rods with pointed ends, motile, evenly stained in young, vigorously growing cultures, but in older cultures showing granulation and uneven staining. The rods were $1.8 \mu \times 0.4 \mu$ to $3 \mu \times 0.6 \mu$, without capsules or iodine-staining polysaccharide. Growth on glycerol slopes (medium 5) gave opaque, light-brown colonies with a creamy periphery. Deep colonies were similar, but the centres were very brown and this colour deepened on prolonged incubation. Suspensions of organisms in saline were sometimes very dark-coloured, almost black.

\section{Table 1. Reactions of glycerol-fermenting selenomonads}

\begin{tabular}{|c|c|c|c|c|c|c|c|c|c|c|c|}
\hline \multirow{2}{*}{ Substrate } & \multicolumn{11}{|c|}{ Isolation number and reaction } \\
\hline & 3 & 6 & 7 & 8 & 9 & 12 & 17 & 18 & 19 & 20 & 21 \\
\hline Xylose & - & - & 一 & - & - & - & + & + & + & + & + \\
\hline Starch & + & + & + & + & + & + & - & - & - & - & - \\
\hline Dextrin & + & + & + & + & + & + & - & - & - & - & - \\
\hline Sorbitol & + & + & + & + & + & + & - & $\rightarrow$ & - & - & - \\
\hline Dulcitol & - & - & + & - & - & - & - & - & - & - & - \\
\hline Inulin & - & - & - & - & - & - & $+*$ & $+*$ & $+*$ & $+*$ & $+*$ \\
\hline Melezitose & + & + & + & + & + & + & - & - & - & - & - \\
\hline Amylose & + & + & + & + & + & + & - & - & - & - & - \\
\hline Nitrate reduction & + & + & + & + & + & + & - & - & n.t. & - & - \\
\hline
\end{tabular}

* Inulin fermentation much slower than other reactions.

n.t. = not tested.

All isolates fermented cellobiose, maltose, glucose, sucrose, glycerol, lactose, mannitol, galactose, arabinose, raffinose, salicin, aesculin, melibiose, ribose, fructose, sodium lactate, mannose, glucose1-phosphate, glucosamine $\mathrm{HCl}$. No isolates fermented trehalose, rhamnose, inositol, adonitol, xylan, cellulose, glycogen, sorbose, sodium acetate, fumarate, citrate, pyruvate, succinate. No isolates liquefied gelatin, formed indole, acetyl methyl-carbinol, or catalase, or grew aerobically. All formed $\mathrm{H}_{2} \mathrm{~S}$ and were motile. All grew at $30^{\circ}$ and $38^{\circ}$, but not at $18^{\circ}$ or $50^{\circ}$.

Cultures were also isolated from sheep 9 in the same manner. In the initial cultures growth and acid formation took place up to $1 / 10^{9}$ dilution. Pure cultures were obtained from this dilution (isolates labelled 17, 18, 19, 20, 21). In morphology and growth the cultures were similar to those from sheep 6 being motile curved Gramnegative rods $1 \cdot 6 \mu \times 0.6 \mu$ to $3 \mu \times 0.6 \mu$. The biochemical reactions of all cultures are given in Table 1. Six isolates tested (numbers 3, 6, 9, 12, 17, 21) showed no lipolytic activity, and two isolates $(3,17)$ tested did not hydrolyse tributyrin. All isolates grew in medium 4 with $10 \%$ or $20 \%(\mathrm{v} / \mathrm{v})$ rumen fluid or in a casitone + yeast medium without rumen fluid, and growth in a rumen fluid-type medium (similar to 4) was much better when casitone or yeast extract was added. As shown later, acetate was not utilized along with the glycerol, but it appeared to act as a growth factor, as growth in medium $4+$ acetate was much better than without acetate at $24 \mathrm{hr}$.; after $48 \mathrm{hr}$., however, growth was much the same in each medium. 
These curved Gram-negative glycerol-fermenting rods appear on morphological grounds (see Fig. 1) to belong to the genus Selenomonas. Since they all ferment lactate they may be classified as $S$. ruminantium var. lactilyticas (Bryant, 1956).

\section{Lipolytic bacteria}

Growth in saliva-based media. Experiments were made in which dilutions of rumen contents were inoculated into medium 10. Although growth was obtained, little lipolysis appeared to be taking place; the following results are typical. Tenfold dilutions of rumen contents from sheep $8 \mathbf{N}$ (fed linseed oil) were made in the diluting fluid and portions transferred to tubes of medium 10, medium 10 without glucose, and medium 10 without glucose and yeast extract. The cultures were incubated vertically in tubes in a shaker with a short, rapid travel. The shaker was kept going for about $7 \mathrm{hr}$. out of every $24 \mathrm{hr}$. during an 8-day period of incubation. The linseed oil emulsion made all the tubes too optically dense to see whether growth had taken

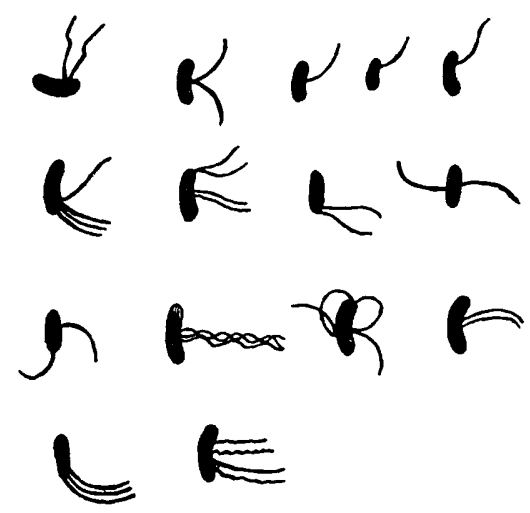

Fig. 1. Arrangement of flagella on glycerol-fermenting selenomonas. Not to scale.

place, but examination of stained films showed that a mixed growth of bacteria with many Gram-positive cocci occurred in medium 10 tubes up to $1 / 10^{6}$ dilution. From $1 / 10^{7}$ to $1 / 10^{12}$ dilutions the growth was mainly small indeterminate Gram-negative rods. Tubes of medium 10 minus glucose showed a similar growth, but the Grampositive cocci were slightly more numerous in the greater dilutions; Gram-negative rods were always present. The tubes of medium 10 without glucose and yeast extract showed a few bacteria in dilutions $1 / 10^{1}$ and $1 / 10^{2}$, but nothing at greater dilutions. A representative number of tubes were taken for determination of lipolysis; the results are shown in Fig. 2. It will be seen that although there was some extra acid formed in cultures in medium 10, with and without glucose, the extent of lipolysis was similar to that produced by dilution of the rumen fluid in medium 10 without glucose and yeast extract, and no lipolysis due to growth of the bacteria in the greater dilutions was detected.

Growth in rumen-fluid based media. Preliminary tests established the composition of the medium which would give a stable emulsion of linseed oil and allow growth of bacteria. The following are the results of a preliminary experiment with medium 11 . Dilutions of rumen fluid from sheep $8 \mathrm{~N}$ in medium 11 were incubated in a nearly horizontal position on a rocking shaker making 1 rock per minute, as it was thought 
that the shaker previously used was too violent. This slow rocking kept the linseed oil emulsion fairly well dispersed, only a slight amount of oil appearing on the surface of the medium. Incubation was continued for 5 days. The 5- to 6-day incubation period was initially used because it appeared to give greatest growth on visual examination of cultures; it was later confirmed that with pure cultures the viable count was higher after incubation for 6 days than for 3 or 10 days. Examination of cultures showed a mixed growth, with many Gram-positive cocci and Gram-negative rods of different shapes and sizes, up to $1 / 10^{9}$ dilution, the greatest made, except for dilutions $1 / 10^{7}$ and $1 / 10^{8}$ where the Gram-negative rods were present in very small numbers. The extent of lipolysis was determined on all tubes and is shown in Fig. 2. The result for the $1 / 10^{5}$ dilution may be low because of a mishap in the extraction, but it is evident that more lipolysis was taking place in general in the greater dilutions than could be accounted for by dilution of the rumen fluid; it appeared to be connected with the presence of Gram-negative rods, so more trials of the medium

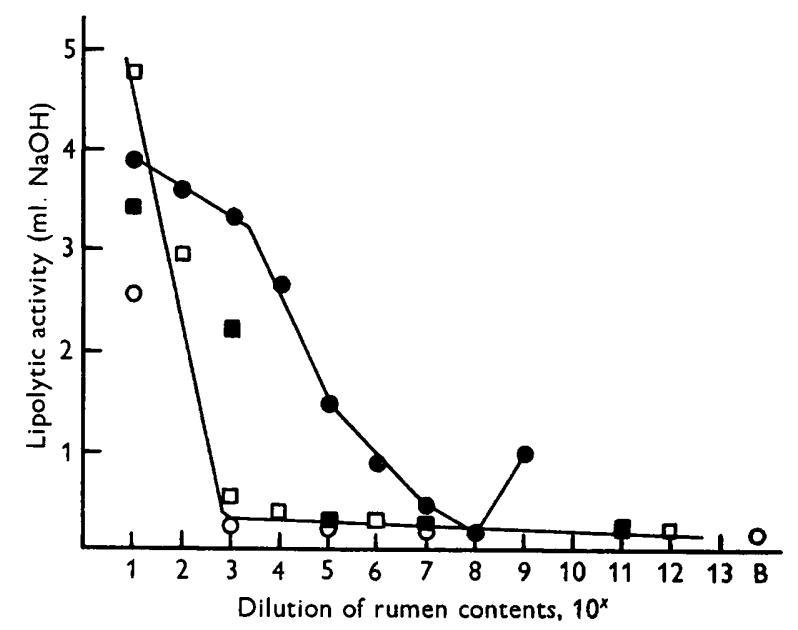

Fig. 2. Lipolytic activity of dilutions of rumen contents cultured in different media. Saliva-based medium: with linseed oil + glucose, $\square$; linseed oil alone, $\square$; linseed oil without nitrogen source, no bacterial growth, $O$. Rumen fluid-based medium: linseed oil + glucose, 0 .

were made. For the isolation of lipolytic bacteria dilutions of rumen contents from sheep $8 \mathbf{N}$ (fed linseed oil) were made in medium 11 and incubated for 5 days. Stained films showed a mixed flora including Gram-positive cocci up to the $1 / 10^{6}$ dilution; from the $1 / 10^{6}$ to $1 / 10^{9}$ dilutions Gram-negative rods of different morphology were the organisms observed. All the dilutions except $1 / 10^{\circ}$ showed lipolysis and from the original $1 / 10^{7}$ and $1 / 10^{8}$ dilutions three isolates of lipolytic bacteria were obtained by dilution and subculture on alternate liquid and solid media (12 and 13). These were small Gram-negative rods labelled $7 \mathrm{ES}, 8 \mathrm{ES}$ and $8 \mathrm{ER}$. The lipolytic activity in liquid medium (12) was tested at intervals while the cultures were kept; it did not diminish on subcultivation. Up to about $70 \%$ hydrolysis of the oil occurred in 6 days. In morphology, growth characteristics and biochemical reactions all these isolates were similar, except that isolate $7 \mathrm{ES}$ grew much more poorly than the others and did not keep so well in stock cultures. The organisms were strictly anaerobic, 
Gram-negative rods variable in size, but generally $1.2 \mu$ to $1.8 \mu \times 0.4 \mu$ in young cultures. They were more or less curved depending on the size of the given organism. Organisms in older cultures became faintly staining and developed a central granule; these organisms were generally larger (up to $3 \mu$ to $3 \cdot 6 \mu \times 0 \cdot 4 \mu$ ). Later the organisms seemed to disintegrate leaving only a granular mass. The organisms were actively motile with a single polar flagellum. No iodine-staining polysaccharide or definite capsules were seen, but organisms of isolates $8 \mathrm{ES}$ and $8 \mathrm{ER}$ were buried in masses of slime. Isolate 7ES was not so noticeably slimy. In glycerol agar colonies were lenticular and brownish. Towards and on the agar surface, colonies were round, raised, whitish and mucoid; on continued incubation, the colonies spread to give a very slimy growth all over the agar surface. In linseed oil agar roll tubes colonies were minute or invisible to the naked eye unless incubation was continued for a long time, and growth was usually noticed only by the circular clear areas which developed in the agar. Clear zones, taken to indicate esterase activity, were formed in the tributyrin medium.

These bacteria hydrolysed linseed oil, but did not apparently utilize the resultant long-chain fatty acids and no growth occurred in a medium containing the acids from hydrolysed linseed oil. Fermentation tests were originally carried out in medium 12+the appropriate sugar in place of oil. Of the substances listed in Table 1 only glycerol, fructose and ribose were fermented, the first more quickly than the others. However, in all cases growth was not luxuriant, so some of the tests were repeated using medium 14. Growth was much better in this medium, but only the same substances were utilized. In medium 12 with glycerol alone the final $\mathrm{pH}$ value was $5 \cdot 6$, in medium 14 it was $\mathrm{pH} 5 \cdot 0$. Hydrogen sulphide was formed, nitrate was not reduced to nitrite, indole was not formed, nor was gelatin hydrolysed. Growth occurred at $38^{\circ}$, but not at $20^{\circ}, 30^{\circ}$ or $50^{\circ}$. In rumen fluid-based media growth was somewhat better when $30 \%$ or $40 \%$ rather than $10 \%$ or $20 \%(\mathrm{v} / \mathrm{v})$ rumen fluid was used. These lipolytic bacteria could not be identified with any of the rumen bacteria so far described.

\section{Products of glycerol fermentation}

Some of the bacterial isolates were tested for the products of glycerol fermentation. The mixed flora growing from $1 / 10^{3}$ and $1 / 10^{4}$ dilutions of rumen contents inoculated into medium 1 produced formic, acetic, propionic, butyric, isovaleric and caproic acids and four clostridial isolates from this medium all produced formic, acetic and butyric acids. Other products were not tested for. The Gram-negative curved rods were all very similar in fermentation products. Isolate $A / 10 / B$, isolated from sheep 8 in medium 4 containing only glycerol (see above), produced mainly propionic acid when grown with glycerol or glycerol + acetate. The six isolates of the selenomonads from sheep 6 all produced mainly propionic acid in a glycerol + acetate medium (6). Selenomonad isolate 3 produced in one experiment ( $\mu$ mole acid $/ \mathrm{ml}$. medium): propionic, $50 \cdot 4$; lactic, $8 \cdot 2$; succinic, 14.6 ; acetic, 4.2 ; no formic or butyric acids. These products accounted for $111.3 \%$ of the carbon of glycerol utilized. In other experiments very slight growth appeared to take place in the medium without glycerol with the formation of some volatile fatty acids. This might account for this high carbon recovery. Selenomonad isolate 21 in the same medium 
produced mainly propionic acid, with some lactic acid (succinic acid not tested for, no carbon balance done). The lipolytic bacteria which utilized glycerol in medium 14 without oil produced mainly propionic acid. In one experiment the products from isolate $7 \mathrm{ES}$ were $(\mu$ mole acid/ml. medium) : acetic, $3 \cdot 4$; propionic, $36 \cdot 2$; butyric, $0 \cdot 6$; succinic, $11 \cdot 0$; no formic or lactic acid. These products accounted for $89 \cdot 1 \%$ of the carbon of the glycerol fermented. Isolates $8 \mathrm{ES}$ and $8 \mathrm{ER}$ behaved similarly. Isolate $8 \mathrm{ES}$ produced in one experiment ( $\mu$ mole acid $/ \mathrm{ml}$. medium): acetic, 6.0; propionic, 54.0 ; butyric, 1.0 ; succinic 8.0 ; no formic or lactic acid; carbon recovery $90.0 \%$. There was no obvious gas formation with glycerol media, but since no quantitative measurements were made, some $\mathrm{CO}_{2}$ or bacterial slime might account, partially at least, for the low carbon recoveries.

\section{Ammonia utilization or formation}

The utilization of ammonia by nine isolates of selenomonads and the three lipolytic isolates when grown in either of the media 8 and 9 was not definitely detected after growth for 2 days. Except in three cases the ammonia concentration in the growing culture was within $0.5 \mu \mathrm{mole} / \mathrm{ml}$. of that of the control. In the three cases the difference was about $1 \mu \mathrm{mole} / \mathrm{ml}$., but it was not consistent and was ignored. Some rumen bacteria have been shown to utilize ammonia when growing in media in which this compound was almost the only source of nitrogen, others have been found to need amino acids or peptides as well as ammonia. The two media described here should have provided both conditions. Growth in medium 9 with added yeast extract was much better than in medium 8 .

\section{Counts of lipolytic bacteria in rumen contents}

Viable counts of lipolytic bacteria in the rumen contents of sheep 9, and of sheep 97 and 186 on the basal ration alone and fed linseed oil were made on medium 13 in roll tubes. The number of clear zones in the medium after incubation for 6-7 days was noted. As it was very difficult to see some of these zones, only approximate counts were made. Clear zones were found in media inoculated from sheep 9 up to $1 / 10^{9}$ dilution, from sheep 97 to $1 / 10^{10}$ and from sheep 186 to $1 / 10^{9}$ on each ration. Although colonies of bacteria not visibly utilizing the oil could be seen, in the smaller dilutions especially, the zones of clearing contained colonies that were barely visible to the naked eye, as with the pure cultures of lipolytic bacteria. On prolonged incubation the colonies and the clear zones became larger, but by this time the majority of bacteria appeared to have disintegrated (compare the pure cultures) and no definite morphological structures could be identified.

\section{DISCUSSION}

It is evident from the experiments with sheep 8 that the addition of glycerol to a rumen fluid medium did not lead to the growth only of bacteria capable of utilizing this compound; many bacteria seem to have requirements such that they can grow on the substrates provided by rumen fluid + yeast extract. However, the media used here should have permitted the growth of a good selection of bacteria able to utilize glycerol even if others grew also. The results show that whilst bacteria like 
those found in other habitats play some part in the rumen fermentation of glycerol, they are present only in small numbers. The results are similar to other reports in which different media have shown similar numbers of bacteria such as Aerobacter aerogenes to be present in the rumen. The numbers in which the selenomonads grew show that they must form a major component of the glycerol-utilizing flora. It is also evident that they are a basic part of the rumen flora and are not found solely or even mainly in the rumen of sheep fed glycerol-containing diets. These selenomonads, however, can utilize a large selection of 'sugars' and so would be expected to exist on substrates provided by almost any diet. Although there are obvious differences in fermentation reactions between the isolates of selenomonads from sheep 6 and 9, in general the reactions agree with those of the two bovine strains of lactate-fermenting selenomonads described by Bryant (1956) which also showed some strain differences. Isolates 3 and 21 were also tested qualitatively for volatile fatty acids formed by fermentation of glucose; propionic acid and acetic acid were the only ones detected. In this these bacteria are similar to Selenomonas ruminantium var. lactilyticas, both strains of which produced mainly propionic and acetic acids from glucose. In general the size of the isolated selenomonads was less than that of the selenomonads seen in the rumen; further experiments are in progress to see whether the bacteria described here are really typical large rumen selenomonads which have become smaller on cultivation in vitro. In the absence of acetate, glycerol fermentation in vitro was much slower than the fermentation of many other carbohydrates, so that the presence of acetate in the rumen would aid in the rapid utilization of glycerol by the selenomonads. Whilst glycerol-fermenting bacteria other than the selenomonads and lipolytic rods are present in the rumen and would contribute small amounts of mixed volatile fatty acids to its contents (e.g. clostridia), the selenomonads and the lipolytic bacteria described here must constitute a significant part of the flora and their products of fermentation of glycerol should bear some relationship to those found in the rumen. The main fermentation product in all cases was propionic acid, with some lactic and succinic acid. The amounts of volatile fatty acid formed differed in different experiments, but were always less than the theoretical amounts provided by the complete conversion of the glycerol utilized; in some cases the amount was only $50-60 \%$ of the theoretical. These results are similar to those found with whole rumen contents in vitro where only a fraction of the glycerol fermented could be accounted for as volatile acids, considered as propionic (cf. Garton et al. 1961). If the other products were lactic or succinic acids one might expect them to be rapidly fermented by the whole rumen contents giving, again, propionic acid. Thus, either other so far unidentified products are formed, or the fermentation of lactate and succinate takes place so slowly under the in vitro conditions used that these products accumulate. That this could happen is shown by the fact that small amounts of lactic acid were found amongst the products of glycerol fermentation by the selenomonads, although these bacteria will utilize lactate when it is the sole substrate present. The selenomonads and the lipolytic bacteria did not utilize ammonia or produce it under the conditions of the test, so no obvious reason appears for the presence of glycerol having an effect on ammonia levels in the rumen.

Other studies on lipid metabolism by bacteria have been mainly confined to aerobic or facultatively anaerobic bacteria growing on substrates containing glycerides of lower fatty acids. In some cases the hydrolysis of esters of the higher fatty 
acids has been demonstrated, again principally with aerobes or facultative anaerobes. In earlier (unpublished) experiments on rumen contents the presence was shown of a small number (about $10^{4} / \mathrm{ml}$.) of bacteria of the genus Bacillus, which were capable of growing on relatively simple media and of hydrolysing tributyrin. The lipolytic bacteria described here seem to be the only ones so far isolated from the rumen which will hydrolyse triglycerides of long-chain fatty acids. Although morphologically similar to many types of rumen bacteria they differ from all known species in their limited fermentation reactions. It would thus appear that they might be put in a new classification, but it is probably better to leave this until further strains are isolated. These bacteria are probably not the only ones which will hydrolyse glycerides in the rumen, but from the numbers present (about $10^{8} / \mathrm{ml}$.) they would appear to have a large part in this action. Again, the bacteria seem to be regular inhabitants of the rumen, and not to be encouraged by feeding linseed oil or glycerol, but all the rations fed to the animals would contain some, if only a very small amount, of lipid. Although these bacteria readily hydrolyse linseed oil they do not apparently metabolize the higher fatty acids formed; this is in accordance with the experiments in which rumen contents were incubated with triglycerides (Garton et al. 1961) where the liberated acids accumulated quantitatively. Further experiments will be needed to see whether these lipolytic bacteria are also responsible for the hydrogenation of unsaturated fatty acids in the rumen. Although the lipolytic bacteria described here were tested for hydrolytic activity only towards linseed oil and tributyrin, it is possible that they will also hydrolyse other triglycerides, as do mixed rumen bacteria (Garton et al. 1961).

The authors would like to thank Miss S. Bell and Miss M. G. Garvock for skilled assistance in this work. They are also indebted to Dr M. I. Chalmers for placing some of the sheep at their disposal.

\section{REFERENCES}

Barker, S. B. \& Summerson, W. H. (1941). The colorimetric determination of lactic acid in biological material. J. biol. Chem. 138, 535.

Bryant, M. P. (1956). The characteristics of strains of Selenomonas isolated from bovine rumen contents. J. Bact. 72, 162.

Bryant, M. P. (1959). Bacterial species of the rumen. Bact. Rev. 23, 125.

Bueding, E. \& Yale, H. W. (1951). Production of $\alpha$-methylbutyric acid by bacteria-free Ascaris lumbricoides. Biochem. J. 74, 180.

Conway, E. J. (1957). Microdiffusion Analysis and Volumetric Error, 4th ed. London: Crosby, Lockwood and Co. Ltd.

Doetsch, R. N., Robinson, R. Q. \& Shaw, J. C. (1952). Techniques employed in cultural investigations of the bacteriology of bovine rumen contents. J. anim. Sci. 11, 536.

Elsden, S. R. \& Lewis, D. (1953). The production of fatty acids by a Gram-negative coccus. Biochem. J. 55, 183.

Friedemann, T. E. (1938). The identification and quantitative determination of volatile alcohols and acids. J. biol. Chem. 123, 161.

Garton, G. A. (1960). Lipid metabolism in herbivorous animals. Nutr. Abstr. Revs. 30, 1.

Garton, G. A., Hobson, P. N. \& Lough, A. K. (1958). Lipolysis in the rumen. Nature, Lond. 182, 1511.

Garton, G. A., Lough, A. K. \& Vioque, E. (1961). Glyceride hydrolysis and glycerol fermentation by sheep rumen contents. J. gen. Microbiol. 25, 215. 
Grant, W. M. (1947). Colorimetric micro-method for the determination of formic acid. Analyt. Chem. 19, 206.

Hungate, R. E. (1950). The anaerobic mesophilic cellulolytic bacteria. Bact. Rev., 14, 1.

Jonns, A. T. (1953). Fermentation of glycerol in the rumen of the sheep. N.Z. J.Sci. Tech. $35 \mathrm{~A}, 262$.

Kонn, J. (1953). A preliminary report of a new gelatin liquefaction method. J. clin. Path. 6, 249.

Lambert, M. \& Neish, A. C. (1950). Estimation of glycerol. Canad. J. Res. 28, 83.

Manual of Microbiological Methods (1957). New York: MeGraw-Hill Book Co. Inc.

Umbreit, W. W., Burris, R. H. \& Stauffer, J. F. (1957). Manometric Techniques, 3rd ed. Minneapolis: Burgess Publishing Co. 